\title{
UM PERCURSO PELA HISTÓRIA DAS IDEIAS: A MOEDA EM KEYNES
}

\author{
Larissa Naves de Deus Dornelas ${ }^{1}$
} Fábio Terra ${ }^{2}$

\begin{abstract}
Resumo: Este artigo tem como objetivo mostrar a história das ideias de Keynes sobre moeda. Neste particular, dedica-se exclusivamente a resgatar a obra do autor, um debate intestino a Keynes, afim de analisar a evolução do pensamento dele acerca da importância da moeda no sistema econômico. A contribuição do artigo reside em oferecer, de forma condensada à um paper, uma discussão feita apenas em livros, portanto mais longos, e em língua inglesa. Embora possa parecer uma contribuição por demais modesta, o artigo percorrerá as principais obras econômicas de Keynes, quais sejam, A Tract on Monetary Reform, de 1923, A Treatise on Money, de 1930, e The General Theory of Empolyment, Interest and Money, de 1936, o que é um esforço notável. O pano de fundo da discussão será o afastamento de Keynes da teoria neoclássica ao longo das referidas obras. Além disso, o artigo discute brevemente como Keynes percebia a institucionalidade da Autoridade Monetária.
\end{abstract}

Palavras-chave: Moeda. Economia Monetária da Produção. Keynes. Política Monetária. Pós-Keynesianos.

\section{A JOURNEY INTO THE HISTORY OF IDEAS: MONEY IN KEYNES}

Abstract: This paper aims to recall Keynes's ideas on money. In this sense, the paper dedicates itself only to recall Keynes's thoughts on this elements money, putting aside several debates on the topic Keynes undertook with a number of other authors. The paper's contributions rests in offering, in a rather short length a debate previously done only in book length documents; moreover, this synthesis will be done in Portuguese, something not yet undertaken. Although this contribution might be seen as a very humble one, we argument it is not the case, as to apprehend the course of Keynes's ideas, it will be analyzed his main economic works, namely the 1923 Tract on Monetary Reform, 1930 Treatise on Money, and 1936 The General Theory of Employment, Interest and Money, which is not a small effort per se. The background to the discussion will be Keynes' departure from neoclassical theory throughout these works. Furthermore, the article briefly debates how Keynes has apprehended the institutional remarks of the Monetary Authority.

Keywords: Money. Monetary Economy of Production. Keynes. Monetary Policy. Post- Keynesian.

\section{UN PERCURSO POR LA HISTORIA DE LAS IDEAS: LA MONEDA EN KEYNES}

Resumen: Este artículo tiene como objetivo mostrar la historia de las ideas de Keynes sobre la moneda. En este sentido, el artículo está dedicado exclusivamente a recuperar la obra de Keynes, a fin de analizar la evolución de su pensamiento sobre la importancia de la moneda en el sistema económico. La contribución del artículo radica en ofrecer, en forma condensada a un artículo, una discusión hecha

\footnotetext{
Universidade Federal do Paraná, Departamento de Economia, Curitiba, Paraná, Brasil, email: larissand6@hotmail.com, https://orcid.org/0000-0002-8852-4313

${ }^{2}$ Universidade Federal do ABC, Centro de Engenharias, Modelagem e Ciências Sociais Aplicadas, São Bernardo do Campo, São Paulo, Brasil, email: fabio.terra@ufabc.edu.br, https://orcid.org/0000-0002-2747-7744
} 
solo en libros, por lo tanto más largos, y en inglés. Aunque parezca una contribución muy modesta, el artículo cubrirá los principales trabajos económicos de Keynes, a saber, A Tract on Monetary Reform, 1923, A Treatise on Money, 1930, y The General Theory of Empolyment, Interest and Money, 1936, que es un esfuerzo notable. El trasfondo de la discusión será la desviación de Keynes de la teoría neoclásica a lo largo de estos trabajos. Además, el artículo discute brevemente cómo Keynes percibió la institucionalidad de la Autoridad Monetaria.

Palabras-clave: Moneda. Economía Monetaria e Producción. Keynes. Política Monetaria. Post-keynesiano.

\section{Introdução}

A teoria keynesiana define o sistema capitalista como economias monetárias da produção. Enquanto tal, o sistema econômico contempla uma série de características, como a incerteza a que estão sujeitos os agentes, implicando-lhes expectativas do futuro ao invés do conhecimento dele; a demanda como lado dinâmico da economia, sendo o investimento a variável determinante do produto e do emprego; a existência de desemprego involuntário; a necessidade de coordenação entre as políticas econômicas para o alcance do pleno emprego, dentre outras. Ademais, a adjetivação monetária destaca que a moeda desempenha papel central. Ao contrário da doutrina neoclássica, que a concebe apenas como intermediário de trocas, para Keynes ela é um ativo e, assim, possui valor e, ao mesmo tempo liquidez absoluta, o que a faz uma alternativa de preservação de riqueza ao longo do tempo. Ser a moeda reserva de valor em um mundo incerto pode fazer com que se a demande em detrimento de outros ativos reprodutíveis: daí decorre a insuficiência de demanda efetiva, problema central do sistema econômico.

Dado seu papel na dinâmica econômica, cabe o questionamento: como evoluiu, no pensamento de Keynes, a moeda? Em pormenor, como Keynes inscreveu as funções e os impactos da moeda na economia ao longo de suas principais obras econômicas? Responder a estas questões é o objetivo deste artigo. Ademais, ao longo do desenrolar da história da moeda em Keynes, um debate paralelo será realizado para mostrar como o autor afastou-se da visão neoclássica da moeda.

Todavia, esse será um debate derivado, e não se pretende que ele seja central. Ele será um trilho secundário a ser explorado ao longo da pesquisa sobre a história da moeda em Keynes. Sem dúvidas, este objetivo paralelo é também tema de relevância na literatura pós-keynesiana, mas que ocuparia um empenho tão amplo quanto o quê o objeto específico deste artigo já compreenderá. Logo, opta-se 
por colocá-lo como um objetivo paralelo. O esforço empreendido para recontar a história da moeda no desdobrar da obra de Keynes tem envergadura, pois percorrerse-ão seus principais escritos econômicos, quais sejam, $A$ Tract on Monetary Reform (Tract), de 1923, A Treatise on Money (TM), de 1930 e The General Theory of Employment, Interest and Money (TG), de 1936. Por isso, a linha lógica a ser seguida no artigo é entender como a moeda, isto é, suas funções e impactos, evolui na obra de Keynes entre 1923 e 1936; é neste interim que se encontra a coesão do artigo.

A contribuição que este artigo oferece é a condensação da história da moeda em Keynes em um artigo e, concomitantemente, em língua portuguesa. Há vários trabalhos em língua inglesa, sejam artigos sejam livros, tais como Biböw (2005), Davidson (2006), Tily (2007), Kicillof (2008), Wray (2006, 2011) apenas para citar referências recentes. Em português, contudo, a maior parte dos trabalhos que lidam com a moeda na obra de Keynes refere-se a ela já em economias monetárias da produção, ou seja, considerando a obra de Keynes entre 1930 e 1936, época em que ele desenvolve esse conceito. Estas análises centram-se também na relação dela com as políticas econômicas em geral, e, especialmente, com a monetária, como Carvalho (1994, 1996, 1999), Amado (2000), Libânio (2004), Ferrari Filho (2006), Paim (2016), mas não ao desenvolvimento da relevância da moeda per se na obra de Keynes. ${ }^{3}$

O debate sobre o papel da moeda em Keynes não é, sem dúvidas, novo, nem para seus críticos, nem para seus seguidores. Neste ínterim, as críticas externas ocorreram logo após a publicação do TM. No bojo destas e também a ilustrá-las, as discussões de Keynes com Hayek acerca deste livro são notáveis, a ponto de Keynes chegar a argumentar que "é essencial para aquela teoria [do TM] negar essas proposições - que o Dr. Hayek coloca em minha boca” (1973b, p. 245, grifos no original). Não obstante, como se observa em boa parte do volume XIII dos Collected Writings of John Maynard Keynes (KEYNES, 1973b), Robertson também foi um relevante interlocutor de Keynes nos debates sobre o TM. Além do TM, há também críticas à concepção monetária de Keynes na TG. Elas se iniciam com a leitura da TG feita por Hicks ao considerar que a contribuição de Keynes se restringiu a analisar situações de armadilha da liquidez, ou seja, a moeda afetaria o

\footnotetext{
3 Uma contribuição particular ao Brasil decorre deste artigo. Alguns programas de pós-graduação do país (e também cursos de graduação) têm disciplinas de formação obrigatória com componentes póskeynesianos. Desta forma, esse artigo se soma à essa literatura em língua portuguesa, ao oferecer, sinteticamente, a evolução da percepção sobre a moeda em Keynes.
} 
sistema apenas neste caso especial, algo bastante distinto do que o autor desenvolveu na TG (CARVALHO, 1992).

No corpo da teoria pós-keynesiana, o debate sobre a moeda em Keynes tomou dois rumos principais: para servir ao debate sobre formas de condução da política monetária (PM), tais como Arestis (1998), Arestis e Sawyer (1998), Arestis e Terra (2017), Carvalho (1994, 1999), Biböw (2002), Dickens (2011), Gnos e Rochon (2006); ou para o extenso debate sobre a oferta endógena, nas suas vertentes horizontalista/acomodacionista e estruturalista. O centro da controvérsia refere-se à forma pela qual a demanda por moeda é atendida: se integralmente, com bancos e Banco Central (BC) a acomodando de forma plena (daí a lógica acomodacionista ou horizontalista, por se ter uma reta horizontal no diagrama oferta de moeda-taxa de juros); ou se parcialmente, a depender da preferência pela liquidez bancária, que pode ou não atender a demanda por crédito. Neste caso, a criação de moeda é da estrutura dos bancos, porém na análise risco-rentabilidade, nem toda a demanda por ela será atendida. Ambos os lados e as controvérsias são bem apresentados na literatura, Kaldor (1982), Moore (1988a, 1988b), Palley (1991, 1994, 2008), Arestis e Sawyer (2006), Fontana (2009), Lavoie (2014), inclusive em língua portuguesa, Carvalho (1993), Costa (1993, 1994), Meirelles (1995), Fiocca (2000), Paula (2003) e Paim (2014). Neste particular do debate sobre a oferta da moeda, uma posição que vem retomando proeminência e controvérsia pós-meados dos anos 2000 é a chamada Modern Money Theory, uma espécie de chartalismo 4 moderno com alguma inspiração keynesiana (WRAY, 2006, 2012, 2014), (NERSISYAN e WRAY, 2016), (TYMOIGNE e WRAY, 2013, 2015) com críticas expressas em Lavoie (2013) e Palley (2014, 2015a, 2015b).

As referências acima constroem o mapa dos principais debates acerca da moeda na obra de Keynes, tanto críticos, quanto seguidores. No que tocam às referências em língua portuguesa, aquelas que trazem uma história monetária, como Carvalho (1994), Fiocca (2000) e Paim (2014, 2016), partem do TM. Dentre as referências em língua inglesa, Wray $(2006,2011)$ é o autor que mais reconta a história da moeda, usando de maneira vasta os trabalhos de Keynes. Em específico sobre a moeda, os livros de Galbraith (1977) e Chick (2010), são contribuições, porém, fazem o debate sobre a história da moeda citando Keynes como fonte de referenciais teóricos e de análise, mas não da evolução da moeda na obra do autor.

\footnotetext{
${ }^{4}$ Para o que é (Neo)Chartalismo veja-se Tcherneva (2006) e Fonseca e Mollo (2012).
} 
Desta forma, este artigo encontra uma lacuna a ser preenchida na literatura póskeynesiana sobre a moeda.

Por último, o escopo deste artigo centra-se em realizar uma discussão interna às ideias de Keynes sobre a moeda, de forma que se prescindirá do resgate das diversas influências, como Marshall, Wicksell e Myrdal, além dos interlocutores, como Hayek, Robertson, Robinson e Kaldor. Atenção será dada especificamente à obra de Keynes, pois, apenas este recorte já contribui com material a substanciar a pesquisa. A inserção de todos os debates relevantes à formação das obras do autor inviabilizaria a escrita de um artigo de síntese, como o que aqui se propõe. Além disso, os debates de Keynes com seus contemporâneos por si só conformariam um extenso objeto de pesquisa e divulgação bibliográfica. Por fim, percebe-se na literatura pós-keynesiana em língua portuguesa, a ausência de artigos que remontem a história das ideias de Keynes acerca especificamente da moeda, como visto na revisão de literatura arrolada nesta Introdução.

Assim, o artigo estrutura-se em quatro seções, além desta introdução e das considerações finais. A primeira analisa o Tract, de 1923, pois é nele que o autor inicia suas considerações acerca do papel da moeda em âmbito teórico geral. Na segunda seção resgata-se o TM, de 1930, considerado um passo intermediário para a constituição da teoria monetária de Keynes que se apresenta, por fim, em 1936 com a TG, objeto da terceira seção. Na quarta seção, baseando-se em Keynes (1932) e em Biböw (2002, 2010) será brevemente apresentada a institucionalidade prevista por Keynes à Autoridade Monetária (AM), debate relevante por ser ela a responsável pela execução da PM, política incumbida do zelo à moeda, objeto deste artigo.

\section{A Tract on Monetary Reform}

No Tract (Keynes, 1971a), o objeto de Keynes são as hiperinflações e as flutuações cambiais na Europa no pós-Primeira Guerra. Inicialmente, ele investiga como as alterações no valor da moeda têm efeitos distributivos diferentes para três classes econômicas - trabalhadores, empresários e rentistas. Com inflação, rentistas transferem riqueza a empresários e trabalhadores. Já a deflação transfere renda no sentido contrário: os rentistas a recebem das outras duas classes. A explicação reside em os rentistas deterem ativos mobiliários que, com anuidades recebíveis contratadas de forma prefixada e sem mecanismos de correção monetária, têm seu 
valor deteriorado pela inflação. Por sua vez, os empresários podem ganhar com a inflação desde que, por um lado, seus custos permaneçam relativamente constantes e, por outro lado, seus preços aumentem. Já os trabalhadores podem requerer maiores salários em linha com os maiores preços, não sendo, então, prejudicados pelo processo inflacionário. Contudo, para que isto ocorra, os empresários precisam concordar em pagar maiores salários, o que depende da percepção deles acerca de seus negócios ao longo do ciclo de preços e do poder de barganha salarial dos trabalhadores.

O autor salienta, porém, que os referidos benefícios da inflação para empresários e trabalhadores podem se dissipar ao longo do tempo por quatro razões. Com inflação persistente, (i) o empresário confunde a valorização nominal de seu patrimônio com ganho de capital e, com isso, pode não realizar novos investimentos, dado que ele compreende estar enriquecendo sem a necessidade de novas aquisições de ativos de capital; (ii) uma inflação contínua desestimula novos investimentos devido à incerteza quanto ao nível futuro de preços, o que atrapalha o cálculo no horizonte de tempo relevante ao investimento; (iii) a classe trabalhadora pode se deparar com a aceleração dos preços que supera o aumento de salários nominais, comprometendo o poder de compra, o consumo e a dinâmica de gastos da economia. E, (iv) com a deterioração de suas renda e riqueza, os rentistas não adquirem novos ativos mobiliários, reduzindo o funding disponível a novos investimentos.

Tendo em vista os distúrbios de uma inflação constante, Keynes (1971a) se pergunta: por que os preços variam? Numa primeira ruptura com a teoria neoclássica, o autor parte da Teoria Quantitativa da Moeda (TQM) para criticá-la e modificá-la a bem de sua versão ser o modelo teórico de explicação do comportamento da moeda e dos preços. Em sua formulação, o volume de moeda retido pelo público é primariamente útil como meio de troca, mas não somente e é determinado pelo poder de compra que eles desejam deter. Este montante de poder de compra depende, por um lado, da riqueza do agente, como na versão original da TQM, mas também dos hábitos dos agentes, o que é uma diferença em relação àquela teoria, sobretudo porque, diferente da riqueza que se altera gradualmente, os hábitos estão sujeitos a movimentações intempestivas e relevam o uso da moeda como reserva de valor.

Tendo isso em mente, Keynes (1971a) desenvolve a sua TQM. De partida, e 
similar à versão neoclássica, o poder de compra retido pelos agentes equivale à uma cesta de consumo, $k$; sendo $p$ o preço de cada unidade de consumo e $n$ o volume de moeda emitido pela $\mathrm{AM}$, de modo que $n=p k$, isto é, "a famosa teoria quantitativa da moeda. Enquanto $k$ permanece inalterado, $n$ e $p$ aumentam e diminuem na mesma proporção, ou seja, quanto maior ou menor a quantidade de moeda, maior ou menor é o nível de preços" (KEYNES, 1971a, p. 63). Indo além da TQM tradicional, o autor considera como variáveis relevantes para definir $n$, os depósitos bancários do público referentes a alguma parcela de sua cesta de consumo, $k$, e as reservas em moeda dos bancos, $r$, estas, em parte determinadas pela $\mathrm{AM}$ e, em parte, pelo comportamento bancário, ambas passíveis de alterações peremptórias.

Então, a TQM de Keynes assume a seguinte forma, $n=p\left(k+r k^{2}\right)$, e as variáveis explicativas do nível $n$ são a riqueza do agentes, seus hábitos, que definem o quanto se guarda de moeda em mãos e o volume deixado em depósitos bancários (resultando em $k$ e $k^{\prime}$ ), além de $r$, que são definidas pela AM e pelos bancos e, assim, novamente $n$ dependerá de comportamentos individuais sujeitos à mudança. Nesta expressão, bem como na TQM original, se mantidos inalterados $k$, $r$ e $k$ ', os preços variam na proporção do estoque de moeda. Entretanto, por que estas variáveis seriam constantes?

Para Keynes (1971a), diferente da teoria neoclássica, os hábitos do público e o comportamento dos bancos se modificam, de forma que $k$, $k$ ' e $r$ se alteram e implicam em desproporção entre $n$ e $p$. Se $p$ é o que afeta a economia no Tract, seu comportamento não tem relação unívoca com $n$. Na TQM de Keynes, há uma relação endógena entre $n, p, k, k$, e $r$, logo, tais variáveis se influenciam mutuamente. Para ilustrar o argumento, torne $n$ exógeno e aplique-se um choque positivo nele, ou seja, a AM aumentou a emissão de moeda. Segundo a TQM original, $p$ responderia em mesma proporção, dada a constância de $k$. Na TQM versão Keynes, contudo, $k, k^{\prime}$ e $r$ podem responder à um choque exógeno de $n$. Desta forma, se o aumento de $n$ implicar um aumento de $r$ por parte dos bancos, $p$ não se altera. Outro exemplo pode ser descrito via choque exógeno em $p$ causada por choques de custos. Maior $p$ pode levar o público a mudar seus hábitos em busca de maior proteção e, dessa forma, alteram-se $r, k$ e $k$, sem que $n$ se altere. Logo, vários caminhos podem impactar $p$ e variações de $n$ podem ser utilizadas para balancear os efeitos das outras variáveis sobre $p$. 
A moeda importa no Tract para muito além de apenas causar inflação. Porém, nesta mesma obra, se percebe Keynes ainda relativamente hesitante em ter com a teoria neoclássica plena ruptura. Prova disso, é ele aceitar a validade da TQM no longo prazo enquanto argumenta que a referida validade não deve ser um guia para nada se fazer contra os movimentos de preço no curto prazo, afinal "no longo prazo estaremos todos mortos" (1971a, p. 65, grifo no original). Por conta disso, o autor, também diferenciando-se da teoria neoclássica, salienta a importância da PM, diante do fato de que "mesmo que uma tal política não seja inteiramente bem sucedida [...] seria uma melhoria em relação à política de ficar-se quieto" (KEYNES, 1971a, p. 35).

Como não poderia deixar de ser, para teorizar a PM no Tract, Keynes (1971a) utiliza-se de sua TQM. Para o mundo neoclássico, sendo a moeda um véu, a melhor PM faz com que o volume de moeda acompanhe o nível de transações da economia, à uma dada velocidade de circulação monetária. Já para Keynes, $n$ é controlada diretamente pela AM e parte de ré compulsoriamente estabelecida pela AM, porém não são estes os únicos determinantes de $p ; k$ e $k^{\prime}$ também explicam $p$, mas não estão sob controle imediato da PM, pois dependem dos hábitos do público e do comportamento bancário. Embora não controláveis, $k$, $k$ ' e $r$, são influenciadas pela PM. ${ }^{5}$

Assim, conclui-se que no Tract é possível perceber que Keynes (1971a) inicia sua ruptura com a teoria neoclássica em relação ao papel da moeda. Embora ainda ressalte tanto que a principal função dela, porém não única, seja permitir a realização de trocas, bem como que a TQM é válida no longo prazo, seu argumento considera que os hábitos do público, $k$ e $k$ ', e o comportamento bancário, $r$, fazem o nível de preços variar em desproporção a $n$. Além disso, os hábitos bancários e pessoais encontram a moeda como reserva de valor (isso explica, por exemplo, porque em uma condição de inflação constante, os rentistas preferirão reter moeda e comprar títulos prefixados). Logo, a PM deve atuar, pois se $p$ relaciona-se com $n, r$, $k$, $k$, a AM pode controlá-los ao administrar as duas primeiras condicionantes e influenciar as últimas duas. Assim, ao menos no curto prazo, portanto, a moeda não é neutra e Keynes, no Tract, inicia sua trajetória rumo à sua economia monetária da produção.

\footnotetext{
${ }^{5}$ Ressalta-se que, dado o padrão-ouro vigente à época, Keynes destaca que a AM deve assegurar a estabilidade da taxa de câmbio. Porém, caso haja incompatibilidade na manutenção do equilíbrio entre os níveis de preços interno e externo, a AM deve ter como objetivo central a manutenção do valor da sua moeda (KEYNES, 1971a).
} 


\section{A Treatise on Money}

O TM é um passo intermediário na consolidação de uma teoria monetária da produção, cuja finalização ocorre nos esboços da $T G$, mas cujo processo de formatação encontra-se a partir do Tract. À diferença deste, no TM Keynes (1971b) abandona a TQM por completo, substituindo-a por uma teoria que, para observar os ciclos de preço, produto e renda nominal, destina-se em parte a investigar a produção de bens de consumo e de investimento, e, em parte, a analisar o dispêndio em investimento vis-à-vis a poupança disponível.

Como variável dependente da investigação no TM permanece o ciclo de preços. Para explicá-lo, Keynes (1971b) lança mão de duas equações, a que denominou fundamentais. Para fins da história da moeda em Keynes, apenas a primeira delas, que explica a dinâmica de preços em agregado, é relevante para o objetivo deste artigo. Neste particular, sejam $\Pi$ o nível de preços, $E$ o nível de renda, $S$ a poupança, I o investimento, $P$ o preço dos bens de consumo, $R$ o volume consumido de bens e serviços, $C$ o volume de novo investimento, de forma que $O$, o produto, é igual a $O=R+C$, e $P$ 'é o preço pago pelo volume $C$; nestas condições, $\Pi$ resulta de:

$$
\Pi=\frac{(P R+P r C)}{o}
$$

Para que se possam ter as variáveis $S$ e I na equação (1), segue-se o raciocínio: se $P R$ é o valor gasto em consumo pela sociedade, $E-S$, a renda nominal menos a poupança, precisa equivaler a $P R$. Da mesma forma, I será igual a $P^{\prime} C$, ou seja, o preço multiplicado pela quantidade do novo investimento. Logo,

$$
\Pi=\frac{(\mathrm{B}-\mathrm{S})+I}{o}
$$

ou,

$$
\Pi=\frac{E}{o}+\frac{(I-S)}{o}
$$

A equação (2) é a primeira das equações fundamentais do $T M$ e denota que 
$\Pi$ depende da diferença entre $S$ e $I$. A lógica é que, dado que $E$ equivale a $O$, afinal o produto é igual à renda, $\Pi$ se equilibra se / for igual a $S$, ou seja, se a parcela não demandada de bens de consumo for gasta em novos investimentos. Assim, $\Pi$ se eleva sempre que I superar $S$, isto é, pressões de demanda em relação à oferta. Por sua vez, sempre que $S$ exceder $I, \Pi$ reduz-se, ou seja, há uma demanda inferior à oferta. Ao fim do ciclo, os estoques de $S$ e / serão iguais, porém, em menor ou maior nível: se há $S$ em excesso à $I$, $E$ se reduz, o que implica menor $S$, igualando-se em menor patamar ao / realizado ao longo do período contábil. Em sentido contrário, excessos de I elevam $E$, resultando em maior $S$, igualando $S$ e I em maior estoque que o período passado. A equação (2) contrapõe-se imediatamente à lógica neoclássica pois a ideia de proporção entre volume de moeda e o nível de preços da TQM não vale, haja vista que a quantidade de moeda sequer está na explicação de $\Pi$. Não obstante, é a relação entre / e $S$ que define, em última instância, $\Pi$. Logo, a questão fundamental é: o que determina / e $S$ ?

O comportamento destas variáveis é explicado pela taxa de juros e sua determinação no mercado monetário, cuja influência de Keynes decorre de Wicksell. Keynes (1971b) pressupõe uma taxa natural de juros "wickselliana" ${ }^{6}$ que iguala ex ante $S$ e I, e uma taxa de juros de mercado, composta por duas taxas, a bank rate (curto prazo) e a bond rate (longo prazo). O comportamento da taxa de juros de mercado vis-à-vis a natural explica as variações de $I$, $S$, e, então, de $\Pi$. Se esta taxa for superior àquela, maior risco é percebido pelos agentes, $S$ é estimulada e $I$ deprimido, e vice-versa. Logo: como se determina a taxa de juros? Entra em cena a moeda e o lado monetário da economia no $T M$, com impactos sobre o âmbito real.

Keynes (1971b) apresenta um modelo que relaciona os lados real e financeiro, representados pelas chamadas circulação industrial e financeira. A primeira é o âmbito da produção corrente, contemplando as transações de bens (de capital e de consumo) e serviços. O produto, o $\Pi$ e a velocidade de circulação da moeda determinam a quantidade de moeda requerida nesta esfera. Já a circulação financeira são as operações com ativos financeiros, em que a moeda é um ativo que flui entre as duas esferas, como uma ponte entre ambas. Nesta circulação ela é um

\footnotetext{
${ }^{6}$ Escapa aos limites deste artigo analisar as influências e relações entre Keynes e Wicksell. Elas podem ser vistas em diversos volumes dos Collected Writings of John Maynard Keynes, além, claro do V, que é o livro I do TM. Para uma discussão sintética, veja-se: Cottrell e Lawlor (1991).
} 
ativo como outro qualquer, mas com liquidez máxima e poder de reserva de valor; na circulação industrial, a moeda é meio de troca.

Com isso, Keynes (1971b) apreende que os desequilíbrios de $S$ e l ocorrem quando o público mantém mais ou menos moeda em mãos. As negociações de moeda se dão na circulação financeira entre os agentes 'ursos' e 'touros'. Os primeiros, cautelosos, são aqueles que, dada a taxa natural de juros, preferem manter moeda ao invés de títulos, esperando um aumento da taxa de juros (desvalorização do valor de face dos títulos). Já os agentes agressivos, touros, novamente dada a taxa natural de juros, preferem títulos em carteira, ansiando ganhos de capital via valorização dos seus títulos. É esta diferença de expectativas sobre a taxa de juros de mercado futura versus a natural que determina o volume monetário transacionado no lado financeiro. Ademais, os recursos disponíveis para o financiamento ao investimento na circulação industrial dependem desta negociação.

Neste particular, notam-se duas rupturas de Keynes (1971b) com a teoria neoclássica. Por um lado, as negociações de moeda afetam a disponibilidade de recursos para o lado real, sendo que, então, ambos os lados não são estanques. Por ser um ativo, a moeda concorre com os demais ativos, inclusive de capital, funcionando como uma alternativa à retenção deles. Logo, ela não é neutra, pois sua escassez na circulação financeira pode levar à não ocorrência de investimento no lado real. De modo alternativo, seu excesso na circulação financeira pode colocar a taxa de juros de mercado abaixo do nível natural, estimulando a poupança, por sinalizar uma excessiva percepção de risco dos agentes. Por outro lado, a velocidade de circulação da moeda não é estável, já que a expectativa sobre os juros de mercado futuros em relação ao natural faz os agentes reterem maior ou menor quantidade de moeda.

O espaço para a atuação da PM, por sua vez, decorre da relação entre as taxas de juros natural e de mercado, o que traz consigo o entrelaçamento entre as expectativas e a atuação da AM. A estabilidade de $\Pi$ é conquistada pela busca da equivalência de $I$ à $S$, algo dependente da relação entre as taxas de juros natural e de mercado. A PM é exercida para influenciar o comportamento desta última e sua operação será feita com a AM estipulando a bank rate, intentando fazer com que uma nova bond rate surja, conformando uma market rate que se aproxime o mais possível da taxa de juros natural.

Keynes (1971c) aponta que os instrumentos mais relevantes para a PM são 
as operações de mercado aberto, a janela de redesconto, e as reservas compulsórias, inseridas pelo autor em uma ferramenta mais ampla, a regulação. Em relação à janela de redesconto, a taxa de juros nela cobrada influencia principalmente a taxa de juros de mercado de curto prazo e, desta forma, o volume de crédito. Ademais, a taxa de redesconto é a arma mais adequada quando a AM quer preservar o equilíbrio externo, pois a bank rate impacta a taxa de juros de curto prazo, fundamental na atração de capitais externos. Reservas compulsórias não têm este poder, pois são instrumentos que resultam em maior rigidez no comportamento bancário, já que se forem alteradas com constância levam à incapacidade de os bancos definirem o quanto podem emprestar. Já as operações de mercado aberto produzem efeito direto sobre a reserva dos bancos e, em consequência, sobre o volume de crédito. Tais operações podem ser rapidamente feitas, dando flexibilidade e liquidez para se alterarem as condições monetárias no curto prazo.

Para o autor, a AM tem a capacidade de fazer seus juros de curto prazo serem os efetivos no mercado. Contudo, sobre a taxa de juros de longo prazo, a AM tem apenas influência, não controle pleno. Embora a AM controle a sua bank rate e por meio disso espalhe efeitos sobre a taxa de juros de mercado, as expectativas dos agentes ursos e touros são o outro fator determinante dos juros de mercado e isso implica que, eventualmente, a direção desejada pela AM para os juros possa não ser alcançada.

Estes elementos pertinentes à PM são relevantes não somente porque mostram que Keynes (1971c) concebe a administração da moeda como fundamental para que os ciclos de $S$ e I não provoquem ciclos de preços, mas também porque representam uma ruptura para com a teoria neoclássica, para a qual, como já mencionado, à PM caberia apenas controlar o estoque de moeda em um nível não inflacionário. No TM a moeda está longe de ser um véu já que sua oferta e demanda repercutem sobre o lado real, bem como a inflação decorre das interações entre uma variável com determinação monetária, a taxa de juros de mercado, e outros dois elementos, $S$ e $I$. Eis porque a PM deve ir além do controle exógeno do estoque de moeda. O uso dos instrumentos da AM deve ser coordenado para atingir o seu objetivo, qual seja, influenciar a taxa de juros de mercado, a bem de a equilibrar com a taxa natural, balanceando $I$ à $S$, a fim de manterem-se os preços estáveis. Tais efeitos, contudo, podem não repercutir da forma desejada, a depender da forma pela qual os agentes reagem às ações da AM. 
Pois bem, expectativas, investimentos e juros continuam a ser centrais na explicação dos ciclos econômicos na TG. Contudo, nesta obra, em diferença ao TM, elas participam de um sistema econômico em que a moeda tem um papel proeminente ao longo do processo produtivo e em que as variações nos preços deixam de ser prioridade como eram antes. Na TG, a importância da moeda decorre essencialmente de ela ser um elo entre o presente e o futuro" (KEYNES, 1973a, p. 293, grifo no original), como se expõe a seguir.

\section{The General Theory of Employment, Interest and Money}

O conceito de economia monetária da produção é anterior à $T G$, decorre de 1933, no caminho para a TG, e nelas "mudanças de pontos de vista sobre o futuro são capazes de influenciar o volume de emprego e não meramente sua direção" (Keynes, 1973a, p. xxii). Outro conceito anterior à TG, mas nela central, é a incerteza. Por existir a incerteza, são expectativas que balizam as decisões de investimento e, neste contexto, a importância da moeda toma forma, como ativo alternativo de preservação da riqueza. Nas palavras de Keynes "nós não podemos sequer começar a discutir o efeito de expectativas alteráveis sobre as atividades correntes senão em termos monetários" (1973a, p. 294).

Nas economias monetárias modeladas pela $T G$, a moeda é unidade de conta, o que a oferta liquidez absoluta para saldar transações à vista; ao mesmo tempo, como há contratos diferidos cotados em moeda, ela possui liquidez no tempo e, então, funciona como reserva de valor e, devido a isso, a moeda é um ativo e configura-se, assim, como uma alternativa de retenção frente a outros ativos. ${ }^{7}$ Para que se possa compreender porque a moeda ganha contornos especiais no sistema econômico - e é daí que ela é hábil a causar transtornos no lado real -, Keynes dedica-se a compreender o que a moeda possui em particular.

O que o capítulo 17 da TG mostra é que à moeda cabem duas peculiaridades, quais sejam, elasticidades de produção e de substituição negligenciáveis (KEYNES, 1973a). A elasticidade de produção negligenciável implica ser a oferta de moeda escassa, uma vez que sua produção não se altera quando seu preço muda. Porém, esta restrição de oferta não é absoluta, mas sim relativa à demanda, que não se modifica quando o preço da moeda se altera: sua elasticidade de substituição é 
negligenciável. Assim, a oferta da moeda é escassa relativamente a uma demanda constante, garantindo à moeda 'valor' ao longo do tempo. ${ }^{8} 9$ Somam-se às suas particularidades, alguns fatores acessórios: o custo de vida em termos de moeda ser mantido mais ou menos constante no tempo, os salários nominais serem de alguma forma rígidos no tempo e os contratos monetários serem diferidos.

Contudo, se a demanda dos agentes se dirige à moeda, ou a seus substitutos próximos, há insuficiência de demanda efetiva por bens e serviços, frustrando os planos dos empresários que se dispuseram a empregar trabalho. Nesse contexto, Keynes (1973a) desenvolve sua teoria da preferência pela liquidez, expressão clara da importância da moeda em economias monetárias. Desta forma, as razões para se demandar moeda (liquidez) são quatro: transação, precaução e especulação, sendo que, após a publicação da TG, Keynes introduziu o quarto motivo, finance (KEYNES, 1937; 1973a).

O motivo transação é o requerimento de moeda para a realização de transações correntes, como compras pessoais e capital de giro comercial. O motivo precaução é a retenção de moeda para atender a acontecimentos inesperados ou oportunidades imprevistas de ganhos, o que ressalta a moeda como reserva de valor. O motivo finance designa a demanda por liquidez pelos empresários para o financiamento dos seus planos de investimento. ${ }^{10}$ Por fim, o motivo especulação é a demanda por moeda com o "propósito de obter lucros" (KEYNES, 1973a, p. 170). Em especial, é sobre ele que a PM atua, a ponto de existir "uma curva contínua relacionando as variações na demanda de moeda para satisfazer o motivo

\footnotetext{
7 Por isso, no capítulo 17 da TG Keynes (1973a) elaborou uma teoria de precificação de ativos, de modo que a decisão entre reter moeda ou títulos se expande para a comparação com qualquer outro ativo.

$8 \mathrm{Na} T M$, a moeda é endógena, criada pelo sistema bancário. Na TG, ela é exógena, criada apenas pela AM. Uma leitura atenta aos pormenores de ambos os livros mostra, contudo, que tais escolhas de Keynes pareciam ter fim de simplificação da apresentação dos argumentos.

${ }^{9}$ Como visto na nota anterior, na TG a moeda é exógena e a $A M$ a controla plenamente. No $T M$, a moeda era endógena, e a AM controlava seu estoque pelos instrumentos open market, janela de redesconto e regulação. Na prática, a moeda é parcialmente exógena, pois a AM pode emiti-la e colocá-la em circulação, mas parcela significativa - sobretudo em países com sistema financeiro mais bem desenvolvido - é endógena, criada pelo sistema bancário. Logo, a escassez relativa da moeda é mantida pelo exercício da PM, que mantém a oferta e a demanda por reservas dos bancos no nível necessário à manutenção dos juros básicos estipulados pela AM. Este debate, contudo, tem controvérsias. Veja-se Arestis e Sawyer (2006). Veja-se Arestis e Terra (2017) para um debate sobre a operação da PM pós-keynesiana.

$10 \mathrm{O}$ circuito finance-investimento-poupança-funding mostra que o investimento ocorre em duas etapas. Primeiro, o finance é um fundo rotativo fornecido pelos bancos, que financiam investimentos que estimulam a economia, gerando renda através do multiplicador keynesiano. A renda é, em parte, gasta em consumo, e, em parte retorna ao sistema financeiro via poupança. Ao final, esta nova poupança transforma a dívida dos empresários de curto prazo (finance) em dívida de longo prazo (funding) (KEYNES, 1937).
} 
especulação com as que ocorrem na taxa de juros, devidas às variações no preço dos títulos e às dívidas de vencimentos diversos" (KEYNES, 1973a, p. 197).

O motivo especulação tem como determinante a taxa de juros. $\mathrm{Na} T G$, os agentes 'touro' e 'urso' à la TM não encontram baliza em uma taxa de taxa de juros natural de inspiração 'wickselliana'. A taxa de juros é explicada pela teoria da preferência pela liquidez, em especial, pelo confronto entre as várias preferências pela liquidez individuais. Saliente-se, ainda, que com a teoria da preferência pela liquidez Keynes (1973a) distancia-se da tradição neoclássica, em que a taxa de juros seria o preço equilibrador da demanda por recursos a investir e da propensão de se abster do consumo imediato, em um mercado não-monetário de fundos emprestáveis.

A partir da lógica do motivo especulação, o autor rejeita a ideia da taxa de juros natural utilizada anteriormente no $T M$, passando a sugerir que todo agente possui uma avaliação subjetiva do que seria uma taxa de juros normal ou convencional. A incerteza sobre variações futuras nos juros é o fator determinante da demanda especulativa por moeda e, ao mesmo tempo, este processo dita, em última instância, o patamar dos juros numa contínua reciprocidade-causal. Então, a taxa de juros relaciona-se intimamente com a preferência pela liquidez e, assim, com a incerteza acerca do comportamento futuro dos próprios juros. Logo, a moeda e o seu preço diferido desempenham um papel fundamental em economias monetárias, ao representar uma variável relevante no cálculo do empresário ao tomar sua decisão de investimento, que em uma economia demand-led, como a monetária da produção, é a variável chave, pois cria emprego e renda.

Por um lado, ao decidir investir o empresário calcula as rendas esperadas do investimento sobre o custo de fazê-lo - eficiência marginal do capital. Por outro lado, compara a eficiência marginal do capital com as taxas de juros que remuneram ativos financeiros, mais líquidos e menos custosos do que os de capital. Para que o investimento ocorra, os últimos ativos devem ter "uma eficiência marginal do capital que seja no mínimo igual à taxa de juros" (KEYNES, 1973a, p. 228). Se em agregado as decisões dos empresários direcionarem-se mais a ativos financeiros, o ritmo de criação de empregos diminuirá. Pois bem, nestas economias, as dificuldades são "resultantes da associação de uma taxa de juros a longo prazo convencional e bastante estável com uma eficiência marginal do capital inconstante e altamente instável" (KEYNES, 1973a, p. 204). Como visto, os investimentos além 
das expectativas empresariais, também dependem da taxa de juros que, por sua vez, depende da preferência pela liquidez dos agentes - bancos inclusive -, da quantidade de moeda ofertada pela AM, e das suas ações de PM.

Logo, em economias monetárias da produção, como deve a AM atuar? Levando em conta as dificuldades de se aumentar o investimento, mas tendo em vista sua importância para a demanda efetiva, o objetivo da AM é realizar a PM a fim de "acomodar as transações de demanda por moeda e de impedir que mudanças preventivas do estado de preferência pela liquidez tenham impacto sobre os preços dos ativos não líquidos" (CARVALHO, 1992, p. 212). Logo, a PM deve influenciar a curva de juros do sistema financeiro para tornar mais atrativo o investimento em ativos de capital vis-à-vis os financeiros.

Em específico, a PM afeta a economia ao influenciar o motivo especulação de demanda por moeda, que é explicado pela incerteza acerca da taxa de juros futura. Assim, abre-se espaço para a PM negociar títulos de dívida pública com os agentes que apostam qual o nível futuro dos juros. Ao alterar a taxa de juros, a AM faz com que os agentes criem diferentes expectativas sobre os juros futuros e, desta forma, eles alteram suas oferta e demanda por moeda no sistema financeiro.

À semelhança do que ocorreu no Tract e no TM, também na TG a PM é uma forma de intervenção econômica bastante relevante, o que é um contraste importante e consistente ao longo da obra de Keynes com a teoria neoclássica. Como já se reiterou, por se invocar uma PM ativa, que controle os níveis de liquidez para que se estimule o investimento sem, contudo, descuidar-se dos níveis de preço e de câmbio, Keynes afasta-se da tradição neoclássica. ${ }^{11}$ Aliás, nota-se que o principal instrumento para a realização da PM é a taxa de juros da AM, cuja efetivação instrumentaliza-se pelo open market, alvo de análise de Keynes deste o TM. Alterações nas circunstâncias atuais ou nas expectativas dos agentes provocam reajustes da disposição deles em manter reservas líquidas e, em consequência, há uma nova posição da taxa de juros, condizente com esse novo cenário. Para tanto, a condição necessária à execução da PM é a diversidade de opiniões, "de fato, se isto não fosse assim, 'operações de mercado aberto' seriam impraticáveis" (KEYNES, 1973a, p. 197, grifo no original).

\footnotetext{
${ }^{11}$ A título de curiosidade: moeda e sua controladora, a PM, são alvo de preocupação de Keynes por toda a TG. Keynes (1973a) faz mais de trinta menções à PM/administração monetária na TG e menos de oito referências no total à política fiscal, administração e políticas orçamentárias. Fica clara a relevância da moeda, e não do fiscalismo, na $T G$.
} 
Logo, pôde-se perceber que na TG Keynes (1973a) aprofunda o fato de que as decisões dos agentes são tomadas num ambiente de incerteza. Para além, ele desenvolve o papel da preferência pela liquidez na determinação da taxa de juros, dando a esta uma natureza monetária, tal qual o fez no TM e contraposto ao caráter de preço de fundos reais emprestáveis da teoria neoclássica. Ademais, tal determinação é apenas parcialmente administrável pela $A M$, uma vez que as expectativas dos agentes sobre a taxa de juros futura determinam, de forma responsiva e paralela à atuação da $\mathrm{AM}$, a oferta e a demanda por moeda. Se a incerteza prevalece, há preferência pela liquidez e os agentes reterão moeda, o que leva, por um lado, à menor oferta de recursos ao investimento, ampliando a insuficiência de demanda efetiva. Por outro lado, provoca-se o aumento da taxa de juros, ampliando os custos de oportunidade dos bens de capital e arrefecendo a dinâmica econômica. Deste modo, a atenção ao comportamento da taxa de juros é bastante necessária, sendo que a AM deve, através da PM, controlar os juros de curto prazo, buscando influenciar os de longo prazo, que são os relevantes para a escala de investimento da economia.

A partir da análise feita até aqui percebe-se a importância dada por Keynes à moeda e à PM, destinada não só a manter o nível de preços estável, meta mais notável no Tract e, em alguma medida no $T M$, como também em perseguir o pleno emprego, claro objetivo da TG. Neste sentido, Keynes progressivamente confere um papel mais relevante à moeda na explicação dos fenômenos econômicos até chegar à sua concepção da economia monetária da produção, em que a moeda é um elemento determinante da dinâmica econômica. Se a moeda importa, a política que com ela lida, PM, também importa. Mas, qual seria a institucionalidade da AM para Keynes? A próxima seção passa brevemente por este debate.

\section{Breves notas sobre a institucionalidade da AM}

O artigo The Monetary Policy of the Labour Party, de 1932, contempla vários pontos da percepção de Keynes sobre a institucionalidade da AM. Em particular, Keynes (1982) apresentou seis proposições sobre a gestão do Banco da Inglaterra que, embora sejam a ele destinadas, podem se estender ao desenho de qualquer AM. A primeira aponta que os interesses de acionistas nos lucros do BC britânico deveriam cessar. Essa proposição, segundo Biböw (2002), é clara distinção entre o 
pensamento de Keynes em 1932 e sua visão anterior, sobretudo de meados de 1913, quando tratava das questões monetárias da Índia, já que ele passa a enxergar o papel privado no Banco da Inglaterra como negativo, por ser algo de interesse e função públicos. A segunda proposição reforça a primeira: a AM deve ser reconhecida como uma instituição nacional, em que interesses privados sejam excluídos. Assim, sua direção deveria ser selecionada por razões públicas, não contemplando privilégios ou interesses particulares.

Já as terceira, quarta e quinta proposições apresentam um caráter mais gerencial. A terceira sugere que a gestão da AM seja sujeita ao governo democraticamente eleito, sendo que decisões que envolvam compromissos maiores da instituição devem obter a aprovação do Ministro das Finanças. Esta proposição indica o papel crucial do governo na escolha das principais linhas a serem seguidas pela AM. A quarta proposta, que se relaciona com âmbitos administrativos e de definição de política, afirma que os princípios do sistema monetário, atinados, por exemplo, à qual o índice de preços utilizar, são normas determinadas pelo Parlamento. A quinta proposição trata da importância da abertura e da transparência que a AM deve manter ao realizar PM. Basicamente, a sugestão é de que "o dia-adia da política do Banco, suas estatísticas, técnicas e objetivos imediatos devem ser tão públicos quanto possível e, deliberadamente expostos a críticas externas" (KEYNES, 1982, p. 131). Por fim, a sexta proposição argumenta que quanto menos direto o controle democrático e mais remotas as possibilidades de interferência parlamentar no exercício da PM - portanto, algo diferente da definição da política em si - melhor será.

Estas seis proposições mostram que a AM deve possuir autonomia para operacionalizar seus instrumentos a fim de alcançar seus objetivos. Dessa forma, sua gestão não deve ser relegada a membros do governo, mas sim a técnicos especializados na gestão bancária, embora sua política geral seja delineada pelo governo no poder. Assim, o governo democraticamente eleito define a política econômica geral, delineando, dessa forma, seus objetivos. Contudo, fica a cargo dos técnicos da AM a tarefa de utilizar os meios necessários para se alcançarem tais objetivos. Logo, "embora a independência do banco central seja, portanto, vista como um meio adequado para uma condução eficiente da política monetária, (...) o controle democrático final sobre a política monetária, no entanto, deve ser mantido" (BIBÖW, 2002, p. 775). Esta noção de independência da AM atribuída por Biböw 
(2002, 2010) a Keynes (1982) se refere tão especificamente à liberdade de operacionalização da política, não sendo, então, similar à ideia de independência da Nova Síntese Neoclássica. Assim, o governo é o responsável pela AM, com base na prerrogativa de que ele dita as linhas de política a serem seguidas pela instituição. Ele é responsável pelo desempenho da política econômica, devendo prestar possíveis esclarecimentos e estar sujeito às críticas da sociedade.

\section{Considerações finais}

Percebem-se rupturas e continuidades no pensamento de Keynes acerca da moeda no decorrer de suas principais obras econômicas. A continuidade refere-se à percepção constante e crescente do autor de que a moeda não exercia o papel que os neoclássicos a atribuíam na economia, uma facilitadora de trocas. Decorre daí outra continuidade, a necessidade de exercício da PM, pois a moeda impacta o lado real da economia. A ruptura também se encontra neste mesmo âmbito da constante preocupação de Keynes para com a moeda, a ponto de o autor romper o modo pelo qual ele a considerava: inicialmente, um elemento cujos efeitos de longo prazo seguiam a lógica neoclássica expressa pela TQM; porém, no TM em diante, a moeda passou a ser um fator de repercussões sobre o curto e o longo prazos com o quê a dinâmica econômica envolve-se indissociavelmente. Em consequência há outra ruptura: variações no nível de preço deixam de ser a preocupação central da PM; elas são substituídas pela questão de como controlar variações nas quantidades, principalmente no emprego.

No Tract, o autor desenvolve seu pensamento ainda com muita referência à doutrina neoclássica, sendo o uso da TQM, e sua validade nos preceitos neoclássicos no longo prazo, as principais manifestações dessa continuidade. Apesar disso, o autor já questionava a sua validade no curto prazo, inserindo a moeda e a relação dos agentes com ela, via hábitos e reservas bancárias, como relevantes na explicação dos ciclos de preço. É sobre estes movimentos dos preços que a PM deve atuar.

No TM há a substituição da TQM por uma teoria em que os ciclos de produto e da renda nominal são contemplados, sendo que a explicação para eles relacionase às circulações industrial e financeira, em uma representação dos lados real e monetário da economia, em que se ressaltam os papéis dos juros, sua determinação 
no mercado monetário, e seus impactos sobre o investimento e a poupança. Em seus apontamentos sobre o modo de condução da PM no TM, Keynes enfatiza que a regulação, as operações de mercado aberto e a taxa de redesconto constituem os seus instrumentos centrais. Eles atuam sobre a estrutura a termo da taxa de juros objetivando estabilizar os juros de mercado com relação ao natural, a fim de impactar sobre poupança e investimento e, então, no nível de preços.

Na TG observa-se a teoria monetária de Keynes em sua forma acabada. Nas economias monetárias a incerteza faz com que as decisões se baseiem em expectativas. Por viverem num ambiente permeado de incerteza, os agentes buscam meios de se precaverem do imprevisível futuro e a moeda, dadas as funções que desempenha e a PM que a mantém crível na percepção dos agentes, representa um ativo seguro para transportar riqueza ao longo do tempo. Assim, liquidez pode ser retida para sanar a demanda por segurança dos agentes. Entretanto, procurar segurança significa demandar um ativo não reprodutível, o que interfere diretamente na dinâmica de criação de emprego e produto.

Se a moeda importa, seu preço, a taxa de juros, também o faz muito além de ser apenas um equilibrador de poupança e investimento, como postula a escola neoclássica. Nesse particular, a incerteza quanto às variações futuras da taxa de juros é o fator determinante da demanda especulativa por moeda. Por isso, Keynes (1973a) observa que esta taxa deve ser influenciada pela AM, que deve levá-la a um nível que estimule a decisão de investir e não crie insuficiência de demanda efetiva. No TM, Keynes preocupa-se com uma variável de definição marcadamente monetária, a taxa de juros, impactar o lado real. $\mathrm{Na} T G$, por conta das especificidades da moeda, será seu preço futuro, ou seja, a taxa de juros, a remuneração básica da economia: seu retorno sempre positivo, liquidez máxima ao longo do tempo, é um porto seguro para os agentes; contudo, sua retenção significa não demanda por trabalho, dada sua oferta escassa, o que implica dinâmica econômica de alguma forma alterada. Keynes sugere, ao longo de suas obras, que a atuação da AM é dificultada com o desenvolvimento dos sistemas financeiros modernos, o que o faz, na $T G$, ser cético quanto à capacidade de a PM, sozinha, alcançar vastos efeitos sobre o lado real da economia.

Para além, Keynes (1982) discute a institucionalidade da AM, indicando que ela deve se guiar pela orientação da política econômica como um todo, delineada pelo governo eleito. Ao mesmo tempo, a AM deve dispor de liberdade operacional 
no manuseio de seus instrumentos visando ao alcance de seus objetivos. Não obstante, a AM não escolhe seus objetivos independentemente do governo e, ademais, deve ser clara e transparente em suas ações, em busca de credibilidade e boa reputação, conduzindo expectativas mais confiantes sobre as suas intenções futuras, de modo que, inclusive, a própria administração da taxa de juros pela PM torna-se mais eficaz. Afinal, se todos os agentes estão incertos acerca do caminho futuro da AM, a PM não tem espaço para ser implementada.

\section{REFERÊNCIAS}

AMADO, A. Limites monetários ao crescimento: Keynes e a não-neutralidade da moeda. Ensaios FEE, v. 21, n.1, 2000.

ARESTIS, P. Post Keynesian monetary economics: new approaches to financial modelling. Cheltenham: Edward Elgar, 1998.

ARESTIS, P.; SAWYER, M. A. The Political Economy of Central Banking. Cheltenham: Edward Elgar, 1998.

ARESTIS, P. Handbook of Alternative Monetary Economics. Cheltenham: Edward Elgar, 2006.

ARESTIS, P.; TERRA, F. H. Monetary Policy in the Post Keynesian Theoretical Framework. Revista de Economia Política, v. 37, n. 146, pp. 45-64, 2017.

BIBÖW, J. Keynes on Central Banking and the Structure of Monetary Policy. History of Political Economy, v. 34, n. 4, pp. 749-787, 2002.

BIBÖW, J. Liquidity preference theory revisited - to ditch or to build on it. The Levy Economics Institute of Bard College Working Paper, n. 427, Annadale-on-Hudson: Bard College, 2005.

BIBÖW, J. A Post Keynesian Perspective on the Rise of Central Bank Independence: A Dubious Success in Monetary Economics. The Levy Economics Institute of Bard College Working Paper, n. 625, Annadale-on-Hudson: Bard College, 2010.

CARVALHO, F. C. Mr. Keynes and the Post Keynesians - Principles of Macroecomics for a Monetary Production Economy. Cheltenham: Edward Elgar, 1992.

CARVALHO, F. C.Sobre a endogeneidade da oferta de moeda: réplica ao Professor Nogueira da Costa. Revista de Economia Política, v. 13(3), 1993.

CARVALHO, F. C.Temas de Política Monetária Keynesiana. Ensaios FEE, v.15, n. 1, p. 3361, 1994.

CARVALHO, F. C.Sobre a centralidade da teoria da preferência pela liquidez na macroeconomia pós-keynesiana. Ensaios FEE, v. 17, n. 2, p. 42-77, 1996.

CARVALHO, F. C. Políticas econômicas para economias monetárias. In: LIMA, G. T.; SICSÚ, J.; PAULA, L. F. (Org.). Macroeconomia Moderna - Keynes e a Economia Contemporânea. Rio de Janeiro: Campus, p. 258-281, 1999. 
CHICK, V. Sobre moeda, método e Keynes - ensaios escolhidos. Campinas: UNICAMP, 2010.

COSTA, F. N. (Im)propriedades da moeda. Revista de Economia Política, v. 13 (50), p. 61 75, 1993.

COSTA, F. N. Sobre o "horizontalismo" da oferta da moeda: tréplica ao Professor Cardim de Carvalho. Revista de Economia Política, v. 14 (53), p. 142-146, 1994.

COTTRELL, A.; LAWLOR, S. "Natural rate mutations: Keynes, Leijonhufvud and Wicksell connections. History of Political Economy, v. 23 (4), pp. 625-643, 1991.

DAVIDSON, P. Keynes and Money. In: ARESTIS, P.; SAWYER, M. A Handbook of Alternative Monetary Economics. Cheltenham: Edward Elgar, p. 139-153, 2006.

DICKENS, E. Keynes's theory of monetary policy: an essay in historical reconstruction.

Contributions of Political Economy, v. 30(1), pp. 1-11, 2011.

FERRARI FILHO, F. As concepções teórico-analíticas e as proposições de política econômica de Keynes. Economia Contemporânea, v. 10, n. 2, pp. 213-236, 2006.

FIOCCA, D. A Oferta de Moeda na Macroeconomia Keynesiana. Rio de Janeiro: Paz \& Terra, 2000.

FONSECA, P. C. D.; MOLLO, M. de L. R. Metalistas x papelistas: origens teóricas e antecedentes do debate entre monetaristas e desenvolvimentistas. Nova Economia, v. 22 (2), pp. 203-233, 2012.

FONTANA, G. Money, uncertainty and time. Abingdon: Routledge, 2009.

GALBRAITH, J. K. Moeda: de onde veio e para onde foi. São Paulo: Pioneira, 1977.

GNOS, C.; ROCHON, L. P. Post-Keynesian Principles of Economic Policy. Cheltenham: Edward Elgar, 2006.

KALDOR, N. The Scourge of Monetarism. Oxford University Press: Oxford, 1982.

KEYNES, J. M. A tract on monetary reform. (1923). The Collected Writings of John Maynard Keynes, v. IV, London: Royal Economic Society/Macmillan, 1971a.

KEYNES, J. M. A treatise on money: the pure theory of money. (1930). The Collected Writings of John Maynard Keynes, v. V, Londres: Royal Economic Society/Macmillan, 1971b.

KEYNES, J. M. A treatise on money: the applied theory of money. (1930). The Collected Writings of John Maynard Keynes, v. VI, Londres: Royal Economic Society, 1971c.

KEYNES, J. M. The General Theory of Employment, Interest and Money. (1936). The Collected Writings of John Maynard Keynes, VII. Londres: Royal Economic Society/Macmillan, 1973a.

KEYNES, J. M. The General Theory and after - preparation. The Collected Writings of John Maynard Keynes, XIII. Londres: Royal Economic Society/Macmillan, 1973b.

KEYNES, J. M. The monetary policy of the Labour Party (1932). The Collected Writings of John Maynard Keynes, v. XV, Londres: Royal Economic Society/Macmillan, 1982. 
KEYNES, J. M. Alternatives theories of the interest rate, Economic Journal, 47 (186), pp. 241-252, 1937.

KICILLOF, A. Fundamentos de la Teoría General - las consequências teóricas de Lord Keynes. Buenos Aires: Eudeba, 2008.

LAVOIE, M. The monetary and fiscal nexus of neo-Chartalism: a friendly critique. Journal of Economic Issues, v. 47(1), pp. 1-32, 2013

LAVOIE, M. Post Keynesian Economics - new foundations. Cheltenham: Edward Elgar, 2014.

LIBÂNIO, G. Temas de política monetária: uma perspectiva pós-keynesiana. Textos para discussão, 229, UFMG: CEDEPLAR, 2004.

MEIRELLES, A. Moeda endógena e teoria monetária da produção. Revista de Economia Política, v. 15 (59), julho-setembro, 1995.

MOORE, B. Horizontalists and verticalists. The macroeconomics of credit money. Cambridge: Cambridge University Press, 1988a.

MOORE, B. The endogenous money supply. Journal of Post Keynesian Economics, vol. 10 (3), pp. 372-385, $1988 \mathrm{~b}$.

NERSISYAN, Y. WRAY, L. R. Modern Money Theory and the facts of experience.

Cambridge Journal of Economics, v. 40 (5), pp. 1297-1316, 2016.

PALLEY, T. The endogenous money supply: consensus and disagreement. Journal of Post Keynesian Economics, v. 13 (3), pp. 397-403, 1991.

PALLEY, T. Competing views of the money supply process: theory and evidence. Metroeconomica, 45 (1), pp. 67-88, 1994.

PALLEY, T. Endogenous money supply: implications for the money supply process, interest rates, and macroeconomics. Political Economy Research Institute Working Papers Series, n. 178. Amherst: UMASS, 2008.

PALLEY, T. Modern Money Theory (MMT): the emperor still has no clothes, 2014. Disponível em: http://www.thomaspalley.com/docs/articles/macro theory/mmt response to wray.pdf. Acesso em março de 2017.

PALLEY, T. Money, fiscal policy, and interest rates: a critique of Modern Monetary Theory. Review of Political Economy, v. 27(1), pp. 1-23, 2015a.

PALLEY, T. The critics of Modern Money Theory (MMT) are right. Review of Political Economy, v. 27(1), pp. 45-61, 2015b.

PAIM, B. Oferta de moeda endógena e taxa de juros exógena: as visões keynesiana e pós-keynesianas. Dissertação (Mestrado), Universidade Federal do Rio Grande do Sul, Faculdade de Ciências Econômicas, Programa de Pós-Graduação em Economia, Porto Alegre, 2014.

PAIM, B. A oferta de moda em Keynes. IN FERRARI FILHO, F.; TERRA, F. H. B. Keynes ensaios sobre os 80 anos da Teoria Geral. Porto Alegre: Tomo, p. 97-126, 2016. 
PAULA, L. F. R. de. Teoria horizontalista da moeda e do crédito: crítica da crítica. Estudos Econômicos, v. 33 (2), pp. 287-323, 2003.

TCHERNEVA, P. R. Chartalism and tax-driven approach to money. In: ARESTIS, P.; SAWYER, M. A Handbook of Alternative Monetary Economics. Cheltenham: Edward Elgar, p. 69-86, 2006.

TILY, G. Keynes's General theory, the rate of interest and 'Keynesian' economics: Keynes betrayed. Nova York: Palgrave Macmillan, 2007.

TYMOIGNE, E.; WRAY, L. R. Modern Money Theory 101: A Reply to Critics. Levy Economics Institute of Bard College Working Paper, n. 778. Annadale-on-Hudson: Bard College, 2013.

TYMOIGNE, E.; WRAY, L. R Modern Money Theory: A Reply to Palley. Review of Political Economy, v. 27 (1), pp. 24-44, 2015.

WRAY, L. R. Keynes's approach to money: an assessment after 70 years. Levy Economics Institute of Bard College Working Paper, n. 438. Annadale-on-Hudson: Bard College, 2006.

WRAY, L. R. Keynes after 75 years: rethinking money as a public money. Levy Economics Institute of Bard College Working Paper, n. 658. Annadale-on-Hudson: Bard College, 2011.

WRAY, L. R. Modern Money Theory - a primer on macroeconomics for sovereign monetary systems. Nova York: Palgrave Macmillan, 2012.

WRAY, L. R. From State theory of money to Modern Money Theory: an alternative to economic orthodoxy. Levy Economics Institute of Bard College Working Paper, n. 792. Annadale-on-Hudson: Bard College, 2014.

\section{NOTAS DE AUTOR}

\section{CONTRIBUIÇÃO DE AUTORIA}

Larissa Naves de Deus Dornelas - Concepção. Elaboração do manuscrito, revisão e aprovação da versão final do trabalho.

Fábio Henrique Bittes Terra - Concepção; Revisão e aprovação da versão final do trabalho.

FINANCIAMENTO

Larissa Naves de Deus Dornelas foi bolsista CAPES em seu mestrado a quem agradece pelo apoio ao desenvolvimento desta pesquisa.

Fábio Henrique Bittes Terra reconhece com gratidão o apoio do Estado Brasileiro a esta pesquisa, por financiamento concedido pelo CNPq.

CONSENTIMENTO DE USO DE IMAGEM

Não se aplica.

\section{APROVAÇÃO DE COMITÊ DE ÉTICA EM PESQUISA}

Não se aplica.

CONFLITO DE INTERESSES

Não se aplica.

\section{LICENÇA DE USO}

Este artigo está licenciado sob a Licença Creative Commons CC-BY. Com essa licença você pode compartilhar, adaptar, criar para qualquer fim, desde que atribua a autoria da obra. 
HISTÓRICO

Recebido em: 20-02-2020

Aprovado em: 13-09-2021 